Olgu sunumu-Case report

\title{
Periferik nabzın elle palpabl olması dolaşımın normal olduğunu gösterir mi?
}

\section{Is the pulses taken with palpation indicate the normal circulation?}

\section{Umut Serhat Sanrı*, Nurkay Katrancioğlu, Oğuz Karahan}

Kalp ve Damar Cerrahisi Anabilim Dalı (Dr. U. S. Sanrı, Doç. Dr. N. Katrancıoğlu), Cumhuriyet Üniversitesi Tıp Fakültesi, TR-58140 Sivas. Kalp ve Damar Cerrahisi Anabilim Dalı (Dr. O. Karahan), Dicle Üniversitesi Tıp Fakültesi, TR-21080 Diyarbakır

\section{Özet}

Periferik arter hastalığı olan olgularda İnternal Torasik Arter (ITA) ve İnferior Epigastrik Arter arasındaki kollateralizasyon büyük önem taşımaktadır. Eğer bu hastalarda koroner arter by pass cerrahisi sebebi ile ITA kullanılır ise birtakım iskemik problemler ortaya çıkabilir. Bu problemler hastanın yaşam kalitesini bozacağı gibi ekstremite kaybına da neden olabilir . Bu olguda kollateral dolaşımın ne derece önemli olduğunu gördük.

Anahtar sözcükler: İnternal torasik arter, obstrüksiyon, kollateralizasyon, inferior epigastrik arter

\begin{abstract}
Collateralization between the internal thoracic artery (ITA) and the inferior epigastric artery is so important for patient with peripheral artery disease. If we use their ITA during coronary bypass surgery some problems may be appear. These problems can affect their quality of life in worse way and can be a cause of extremity lose. In this case we saw the importance of collateral circulation for patients with peripheral artery disease.
\end{abstract}

Keywords: Internal thorasic artery, obstruction,collateralization, inferior epigastric artery

Geliş tarihi/Received: 10 Mayıs 2013; Kabul tarihi/Accepted: 29 Kasım 2013

\section{*Iletişim adresi:}

Dr. Umut Serhat Sanrı, Kalp ve Damar Cerrahisi Anabilim Dalı, Cumhuriyet Üniversitesi Tıp Fakültesi, TR-58140 Sivas. E-posta: ussanri@gmail.com

\section{Giriş}

Ateroskleroz global olarak tüm arter sistemini etkileyebilen multisistemik bir hastalıktır $[1,2]$. Periferik vasküler tıkayıcı hastalıklar da sıklıkla aterosklerozun eşlik ettiği, yaşla birlikte sıklığı artan önemli kardiyovasküler morbidite ve mortalite sebeplerindendir [3].

Genellikle darlığın derecesine göre ayaklarda ağrı, solukluk veya morarma veya kladikasyo gibi bulgularla kendini gösterir [4]. Segmenter tutulum göstermesi, kan akımının kollateral denilen yan yollarla devamlılığını sağlanmasını kolaylaştırdığı gibi, revaskülarizasyon işlemlerine de olanak sağlar $[2,5]$.

Özellikle koroner arter hastalarında, revaskülarizasyon için en önemli seçenek olan internal mammarian arter de, aorto iliak arterial tıkayıcı hastalığı olan vakalarda, periferal dolaşımının devamlılığının sağlanmasında potansiyel bir kollateral yolaktır [6]. Leriche Sendromu gibi femoral yatağa kan akımının sağlanamadığı durumlarda internal mammarian arter yolu ile vasküler devamlılı̆̆ın sağlandığ 1 olgular literatürde önemle vurgulanmıştır [7]. 


\section{Olgu sunumu}

Yaklaşık üç gündür, sol bacağında uyuşma, şikayeti olan 48 yaşındaki erkek hasta Kalp ve Damar Cerrahisi servisine yatırıldı. Hastanın altı yıl önce CABG ve iki yıl önce de Aortobifemoral Bypass operasyonu geçirdiği öğrenildi. Yapılan fizik muayenesinde sol alt ekstremitede femoral arter nabzının Doppler ile trifazik mevcut olduğu distalindede el doppleri ile monofazik akım alındığı görüldü. Sağ alt ekstremitede ise femoral nabzın elle +1 distallerinde ise el Doppleri ile trifazik akım paterni şeklinde alındığı tespitedildi. Bunun üzerine çekilen Aortofemoral DSA da aortadan verilen kontrastın sol internal iliak arterden kollateraller vasıtası ile perineye ve süperfisial femoral artere zayıf geçişi ve aortobifemoral bypass a ait greftinde total oklüze olduğu görüldü (Figure 1). Sağ femoral bölge dahil olmak üzere başka bir vasküler kontraslanma izlenemedi. Sağ femoral bölgede nabızın zayıfta olsa elle alındığı göz önüne alınarak kontrastlama seviyesi yükseltildi. Sağ İnternal torasik arterde (İTA) dilatasyon dikkat çekici idi.( Figure 2, 3) Bunun üzerine selektif yapılan İTA DSA da ITTA ile İnferior epigastrik arter arasındaki kollateralizasyonun artış gösterdiği (Figure 4) ve sağ femoral arterin bu yolla iyi sayılabilecek derecede kanlandığı görüldü (Figure 5). Hastaya iloprost $40 \mathrm{mcg} / \mathrm{gün}$ ve $500 \mathrm{mg}$ pentoksifilin/gün tedavisi başlanarak gözleme alındı.

\section{Tartışma}

Ateroskleroz multisistemik hastalıktır ve bir bölgede saptanması diğer bir bölgede görülme olasılığını arttırır. Yapılan bir çalışmada periferik arter hastalığı ile izlenen hastalarda koroner arter hastalığı sıklığı \%61,4 olarak saptanmıştır [8]. Bu nedenle ateroskleroz ne bölgede olursa olsun sistemik değerlendirilmelidir.

Koroner arter hastalığı için koroner bypass cerrahisi hala en seçkin tedavi yöntemidir. Koroner revaskülarizasyon için seçilecek greftler arasında internal torasik arter (ITA), 15 yıllık \%90 - 95 gibi yüksek bir açık kalma oranı ile hala en önemli greft seçeneğidir [9]. (kaynak ekledi.) Bu nedenle özel durumlar dışında, bypass için hemen her zaman öncelikli seçenektir. Ancak çift taraflı kullanılması düşünüldügünde ek durumlar değerlendirilmelidir. ITA göğüs duvarından aşağıya seyrederek, periferde inferior epigastrik arter aracılığılla kollateral destek verir [10]. Aort koarktasyonunda da bu kollaterallerin distal dolaşıma katkısı açıkça gösterilmiştir [11]. ITA'in periferik vasküler hastalıklarda da alt ekstremite dolaşımına katkıda bulunduğu daha önceki çalışmalarda gösterilmiştir. Zaizen ve ark. [10]'nın sundukları çalışmada internal torasik arter ile exernal iliak arter arasında kollateral dolaşım bir olgu eşliğinde anlatılmıştır. Kolluri ve arakadaşları aorto iliak tıkanıklığı olan bir olguda internal torasik arter ile inferior epigastrik arter kollateralizasyonunu göstermişlerdir [6]. Arnold ve ark. [7] ise Leriche Sendromunda distal yatağın internal torasik arter ile kanlandığı 4 olguyu raporlamışlardır. Bizim olgumuzda da hem perifer hem koroner atroskleroz nedeni ile geçirilmiş bir dizi operasyon öyküsü mevcuttu. Sistemik atrosklerozu olan olgu daha sonra kladikasyo şikâyeti olması nedeniyle başvurduğunda daha önce aorto iliak dolaşımın olmadığını ve bu nedenle uygulanmış aorto bifemoral greftin de tıkalı olduğu izlenmişti. Sağ periferik nabızların elle alınması nedeni ile yapılan üst inceleme de sağ dolaşımın sağ internal torasik arterin inferior epigastrik arter kollateralizasyonu ile dolaşımın sağlandığını ancak sol internal torasik arterin koroner revaskülarizasyon için kullanılması nedeni ile solda kollateral dolaşımın olmadığını ve iskemi oluştuğunu gözledik.

Sonuç olarak fizik muayene ile vasküler dolaşımın olması, dolaşımın her zaman tabi seyrinde olduğu anlamına gelmez. Sisteimk aterosklerozu bulunan hastalarda şüphelenilirse mutlaka kollateral dolaşım değerlendirilmelidir. Ayrıca bu hastalarda kollateral dolaşımın ileride hayati önem taşyacağı düşünülerek, uygulanacak işlemlerde kollateral sistemin korunmasının gerekli olduğu kanaatindeyiz. 


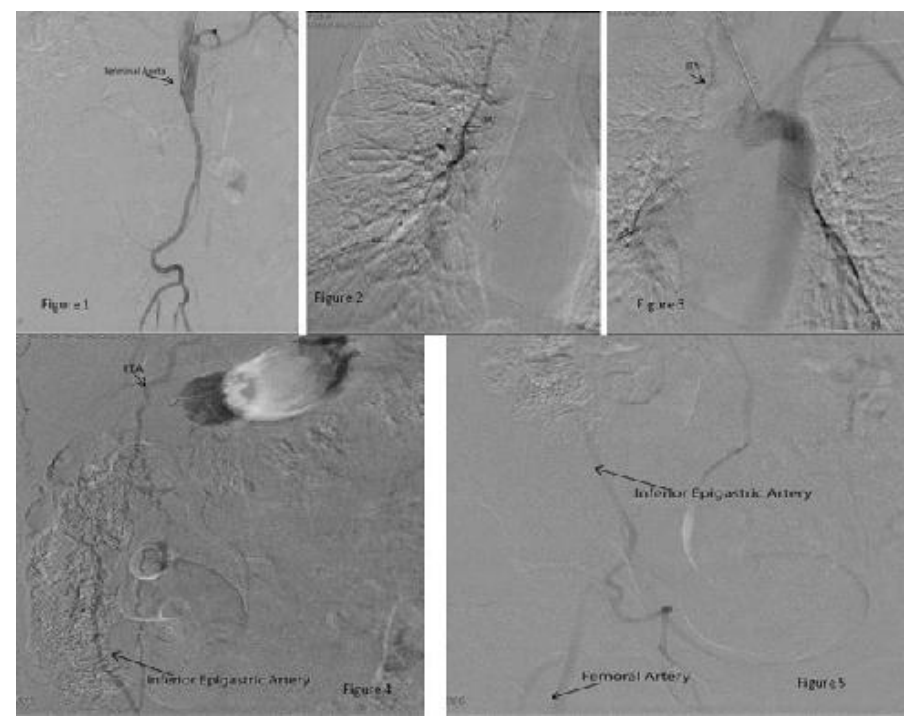

Figure 1. Terminal Aorta'dan perineuma zayıf kontrast geçişi. Figure 2, 3. Sağ internal torasik arterde belirgin dilatasyon. Figure 4. İnferior epigastrik arter ile İnternal torasik arter arasında belirgin artış gösteren kollateralizasyon. Figure 5. Să̆ femoral arterin İnferior epigastrik arter yolu ile vizualize edilmesi.

\section{Referanslar}

1. Tonelli C, Finzi G, Catamo A, Silvestrini C, Squeri M, Mombelloni A, Ponari O. Prevalence and prognostic value of peripheral arterial disease in stroke patients. Int Angiol 1993; 12: 342-3.

2. Lavi S, Bae JH, Rihal CS, Prasad A, Barsness GW, Lennon RJ, Holmes DR Jr, Lerman A. Segmental coronary endothelial dysfunction in patients with minimal atherosclerosis is associated with necrotic core plaques. Heart 2009; 95: 1525-30.

3. Şatiroğlu Ö, Bostan M, Çiçek Y, Çetin M, Bozkurt E. Periferik Arter Hastalığı Yaygınlığıyla Aterosklerotik Risk Faktörleri Arasında İlişki. Selçuk Üniv Tıp Derg 2011; 27: 213-8.

4. Murrant CL. Structural and functional limitations of the collateral circulation in peripheral artery disease. J Physiol 2008; 586: 5845.

5. Kalka C, Baumgartner I. Gene and stem cell therapy in peripheral arterial occlusive disease. Vasc Med 2008; 13: 157-72.

6. Kolluri R, Holloway R, Mishkel G. Images in vascular medicine. Internal mammary artery and inferior epigastric artery collateralization in a patient with aortoiliac occlusive disease. Vasc Med 2009; 14: 93-4.

7. Arnold JR, Greenberg J, Reddy K, Clements S. Internal mammary artery perfusing Leriche's syndrome in association with significant coronary arteriosclerosis: four case reports and review of literature. Catheter Cardiovasc Interv 2000; 49: 441-4.

8. Tünel HA, Manduz Ş, Katrancıoğlu N, Karahan O, Berkan Ö. Determining the risk and frequecy of coronary artery disease in patients who have peripheric vascular occlusive disease and who will have vascular surgery. Türk Göğüs Kalp Damar Cer Derg 2009; 17: 261-6.

9. Taggart DP. Current status of arterial grafts for coronary artery bypass grafting. Ann Cardiothorac Surg 2013; 2: 427-30.

10. Zaizen H, Tamura A, Miyamoto K, Kadota J. The collateral pathway from the left internal thoracic artery to the left external iliac artery detected by multislice computed tomography. Int J Cardiol 2007; 117: e56-7.

11. Leschka S, Alkadhi $\mathrm{H}$, Wildermuth S. Images in cardiology. Collateral circulation in aortic coarctation shown by 64 channel multislice computed tomography angiography. Heart 2005; 91: 1422. 